\title{
Dongxiang Chinese
}

National Cancer Institute

\section{Source}

National Cancer Institute. Dongxiang Chinese. NCI Thesaurus. Code C158179.

A Chinese person from the Dongxiang ethnic group. 